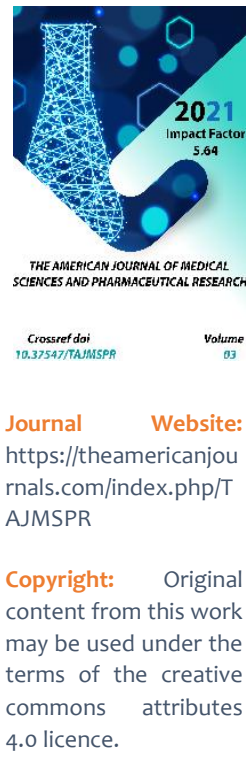

\title{
Dental Fear In Children And Ways To Overcome Them
}

Ortikova N.X.

Samarkand State Medical Institute, Samarkand, Uzbekistan

Rizaev J.A.

Samarkand State Medical Institute, Samarkand, Uzbekistan

\section{ABSTRACT}

Fears and anxieties are part of the normal development of a child, and, as a rule, developmental fears and anxieties are transient. However, for some children, dental fears and anxieties persist and become persistent and problematic. Many different mechanisms have been proposed to explain the development of CVD in children; however, there is general agreement that the aetiology of childhood CVD is multifactorial. Endogenous sources of CVD are internal factors that make people susceptible to the development of dental anxiety. It is important to understand that the influence of close family members can help or hinder treatment. Endogenous factors that can increase a person's susceptibility to CVD include genetic vulnerability, personality traits, age and gender. A high level of CVD among young people is associated with social, emotional and behavioural problems, general anxiety and the temperamental trait of negative emotionality. Having fears and anxieties is considered part of a child's normal development and follows a consistent and predictable pattern of adult life. Poor communication between the dentist and the patient not only contributes to the development of CVD but plays an important role in maintaining dental anxiety. Therefore, all members of the dental staff must be aware of how their behaviour can affect children.

\section{KEYWORDS}

Dental fear and anxiety, the behaviour of children at the reception, correction of fear and anxiety.

\section{INTRODUCTION}

Strategies for correcting dental anxiety and anxiety (DF) in children include, but are not limited to, minimally invasive dental approaches such as atraumatic restorative 
treatment (AVL) $[8,23]$ and chemicalmechanical removal of caries (CMC) $[10,15,19]$; hypnosis [7]; behavioural interventions or behavioural management techniques [6]; music [20]; relaxation [18] and pharmacological agents [18], including the use of benzodiazepines and antidepressants. Medicines provide only short-term effective solutions, but relapse rates are high and the risk of drug side effects is increased [12].

Choosing the right treatment for dental anxiety is not always easy. The collaborative dental patient is critical to the success of the treatment, which is why it is important for the dentist to manage the psycho-emotional state of the patient, especially the child.

Some countries have established specialized dental clinics for adult patients with severe dental anxiety, and these clinics provide specialized care, including both nonpharmacological and pharmacological treatment. In addition to helping treat dental anxiety in patients, these clinics facilitate the provision of dental care in the short and long term [27].

\section{MATERIALS AND METHODS}

Atraumatic restorative treatment (AVL) / chemomechanical removal of caries (HMUK). AVL and HMUK are considered as alternative approaches to traditional methods of caries removal using local anaesthesia and rotating instruments. AVL is a minimally invasive approach that involves the removal of cariesdamaged hard tissue using hand instruments, followed by restoration of the cavity with an adhesive restorative material, usually glass ionomer cement [23]. Since the dental handpiece is one of the triggers of dental anxiety, AVL eliminates the sight and sound of the handpiece, thereby potentially reducing stomatological anxiety [8, 23].

In addition, AVL allows manipulation without injections [8, 23].

AVL can be performed in very young children with dental fear or anxiety, or in patients with special needs [22].

Hypnosis is defined as an interaction in which the hypnotist uses suggestive techniques or scripts to shift the focus of a person to inner experience and influence the perception, feelings, thinking and behaviour of the subject [7]. Hypnosis is useful for correcting CVD, pain control during dental treatment and extraction, for improving the tolerance of orthodontic appliances, as an adjunct to inhalation sedation.

Music. It is a form of relaxation that can have a positive effect on the patient, facilitating concentration and easing anxiety [20]. Music can divert attention from stressful stimuli, stimulate a feeling of physical and mental relaxation, reorienting attention to pleasant emotional states and blocking unpleasant sounds from the environment [20].

Studies show that active music therapies with medical groups are statistically significantly more effective than passive music interventions [16].

Studies have shown that musical intervention reduces surgical stress, induces relaxation, and lowers blood pressure, heart rate and respiratory rate during surgery under local anaesthesia in medical teams [17].

The review of Moola S. et al. (2011) [20] concludes that for musical intervention to be effective in reducing CVD, it is important to consider the type of music, volume, type of 
headphone and patient's preferred music choice. Music helps relieve anxiety due to its effects on the nervous and immune systems.

Dental waiting room. Minor changes made to the design of the waiting room can have a significant impact on how any child perceives the upcoming dental experience [17]. A child's perception of the dental environment is a significant contributor to dental anxiety. Uma Maheshwari et al. (2013) noted that the colour of the walls of the room can have a positive influence on the behaviour of the child [26].

To solve the objectives of this study, the prevalence of CVD in children at outpatient dental appointments was identified, as well as the development of methods for its correction. The study was conducted on the basis of the Samarkand State Medical Institute in 20 20-202 1 years.

Patients who applied to the dental clinic were divided into two groups - the control group (46 children) and the main group (54). In the control group, the number of boys was 27 , girls -19. In the main group, there were 30 boys and 24 girls. The examined children, according to the physiological and biochemical age norms, were divided into age groups (Table 1).

TABLE 1. Age periodization of patients in the main and control groups

\begin{tabular}{|c|c|c|c|c|}
\hline Age & \multicolumn{2}{|c|}{ Main group } & \multicolumn{2}{c|}{ Control group } \\
\hline & Boys & Girls & Boys & Girls \\
\hline 6 & 4 & 3 & 4 & 3 \\
\hline 7 & five & 4 & 4 & 3 \\
\hline $8-9$ & 6 & five & 6 & 4 \\
\hline $10-11$ & five & five & five & 4 \\
\hline 12 & 3 & 3 & 2 & 2 \\
\hline $13-14$ & 3 & 2 & 3 & 2 \\
\hline fifteen & 4 & 2 & 3 & one \\
\hline & thirty & 24 & 27 & nineteen \\
\hline & 54 & & 46 & \\
\hline
\end{tabular}

The tasks of the psychological and sociological research included: assessment of emotional tension, detection of stomatophobia, objective assessment of the behaviour of children at a dental appointment, identification of factors that cause dental anxiety. The tasks of the study of the somatic status included: measurement of diastolic blood pressure, measurement of heart rate, followed by calculation of the Kerdo autonomic index. The tasks of biochemical research included: studying the concentration of salivary cortisol and determining the rate of salivation. Examination of patients, treatment procedures were carried out in a standard dental chair, using a dental probe and a mirror. Objective data were entered into the survey card. 
TABLE 2. General characteristics of clinical material

\begin{tabular}{|c|c|}
\hline Areas of clinical research & Number of surveyed \\
\hline \multicolumn{2}{|c|}{ Study of the somatic status and activity of the ANS } \\
\hline Measurement of blood pressure BP & 100 \\
\hline Determination of heart rate heart rate & 100 \\
\hline Calculation of the vegetative Kerdo index & 100 \\
\hline \multicolumn{2}{|c|}{ Psychological and sociological research } \\
\hline MDAS test & 86 \\
\hline Korach test (DAS) & 86 \\
\hline Luscher color test & fourteen \\
\hline Frankl test & 86 \\
\hline Identifying a Factor Causing Dental Anxiety & 86 \\
\hline Biochemical research methods & 100 \\
\hline Study of the prevalence and intensity of caries & 100 \\
\hline Oral Hygiene Study (OHS) & 100 \\
\hline
\end{tabular}

Changes in the activity of the autonomic nervous system are the result of the influence of dental anxiety experienced by the child. Fear and anxiety are the reason for the development of autonomic reactions that affect the functioning of the cardiovascular system $[2,3,5]$. An indicator of the ANS activity changing under the influence of psychoemotional tension is the Kerdo vegetative index, for the calculation of which the values of heart rate and diastolic blood pressure are required.

To do this, the children were twice measured heart rate and blood pressure - before and after the use of NFMKPN.

The Frankl behavioural scale was used - an objective assessment of anxiety, according to which the behaviour of children at the dental clinic can be divided into four categories:

- Absolutely negative, in which treatment is refused;

- Negative - treatment is accepted with reluctance;
- Positive - treatment is accepted, with caution;

- Absolutely positive - good contact with the doctor, laughter and joy of the child.

The rate of salivation and the concentration of cortisol in saliva were studied. It is known that these indicators are biomarkers of psychoemotional stress and the possibility of non-invasive obtaining makes them very convenient for studies like the present $[1,4]$.

Saliva collection was carried out according to WHO recommendations: in the morning (8-10 am).

Preparation for research includes:

- Cessation of physical activity on the eve of the study;

- The day before the study, it is prohibited to drink alcohol;

- For 1 hour before collecting saliva, do not eat or brush your teeth.

The patient spit saliva into a graduated tube for 10 minutes. After that, in the laboratory, the amount of the resulting liquid was divided by 
the collection time (10), thereby obtaining the salivation rate $(\mathrm{ml} / \mathrm{min})$. The rate of salivation of $0.29-0.41 \mathrm{ml} / \mathrm{min}$ is considered the norm [4].

The concentration of cortisol in the mixed saliva was measured using a semiautomatic biochemical analyzer "Mindray" by the spectrophotometric method. We used HUMAN reagents.
In a sociological study to identify the causes of dental anxiety, it was found that the greatest concern is the expectation of pain $-50 \% \pm 2.15 \%$. The next major irritant was local anaesthesia (injections) $-33 \% \pm 2.97 \%$; $32 \% \pm 2.3 \%$ of patients worried about the sound of the turbine handpiece; the light of the dental lamp caused psychoemotional stress in $3.8 \% \pm 1.1 \%$, and the dentist's comments on oral health - in $2.7 \% \pm$ $1.3 \%$ of children.

TABLE . The results of a sociological survey to identify the causes of dental anxiety.

\begin{tabular}{|c|c|c|}
\hline Irritants & Number of patients (\%) & \multirow{6}{*}{$\begin{array}{l}\text { * - Statistically } \\
\text { significant differences } \\
\text { were calculated in } \\
\text { relation to the response } \\
\text { "expectation of pain" ( } \mathrm{p} \\
<0.05)\end{array}$} \\
\hline Waiting for pain & $50 \% \pm 2.15 *$ & \\
\hline Local anesthesia (injections) & $33 \% \pm 2.97$ & \\
\hline Turbine sound & $32 \% \pm 2.3$ & \\
\hline Dental lamp light & $3.8 \% \pm 1.1$ & \\
\hline Dentist reviews about oral health & $2.7 \% \pm 1.3$ & \\
\hline
\end{tabular}

\section{RESULTS AND DISCUSSION}

Thus, with tomatologic anxiety and dentophobia in children and adolescents - the reason for often late seeking dental care, leading to a complication of the treatment process and worsening prognosis; these patients have poor contact with a specialist and often do not follow his recommendations. $T$ akzhe, they reduce the effectiveness of local anaesthesia, resulting in a need for additional injections of anaesthetic, and the present study found that injections are a major irritant for children - 33\% $\pm 2,97$ patients believe injections cause for concern.

You should also avoid, if possible, excessive criticism about the patient's oral cavity, and spend more time on the prevention of the further development of existing dental diseases. the main attention in preparing children for dental treatment, the pediatric dentist should pay an explanation about the safety of the sound of the turbine handpiece; painlessness of local anaesthesia (with a demonstration of the used thin small needles) and subsequent manipulations after the onset of anaesthesia. In addition, it has been found that anxiety during dental treatment leads to inadequate cooperation with the dentist, which leads to unnecessary difficulties in performing dental procedures and unsatisfactory results. It was found that not enough attention is paid to psychotherapeutic methods of correcting psychoemotional stress, despite their undoubted advantages.

As a result of the use of NFMKPN in children, significant differences are revealed in the studied indicators of the two groups. A significant difference was revealed between the physiological, biochemical, psychological indicators of patients in the main and control groups. That is, it can be argued that the use of 
the proposed methodology reduces the risk of developing emergency conditions in the present and dentophobia in the future. Different conditions for the provision of dental care are being created - more comfortable for both patients and doctors, which reduces the risk of dental burnout.

\section{CONCLUSION}

Based on the fact that the NFMKPN have shown their effectiveness in the practice of pediatric dentistry, which is proved by the lower $\mathrm{RK}$ and $\mathrm{Cl}$ in children of the main group, the better hygienic state of the oral cavity, we consider it necessary to widely introduce the technique into practical health care.

Its advantages include safety, lack of side effects; easily absorbed and applied by a doctor; a comfortable relationship is established between the pediatric dentist and the patient, which improves the ability to provide quality care and reduces the risk of emotional burnout of the specialist; reducing the risk of emergencies; reducing the risk of developing dentophobia in the future. And Using NFMKPN n Allows you to increase the clinical efficacy st dental treatment.

\section{REFERENCES}

1. Bilinsky I.I., Dobrovolskaya M.K., Bilinsky A. Ya. (2017). Changes in the biochemical properties of saliva and their effect on the dental status of students under the influence of stress. Scientific works of Vinnitsa National Technical University, vol. 1, pp. 1-6.

2. A.E. Kulagin, A. V. Sikorsky, A. M. Chichko. (2014). Arterial hypertension and hypotension in children: pathophysiology, clinic, emergency therapy: textbook. Method. Allowance. Minsk, BSMU, 43 p.

3. I.O. Pohodenko-Chudakova, T.N. Terekhova, I.E.Shott. (2010). Psychoemotional stress of children at the dental appointment. Materials 9th Intern. nauch. Pract. conf. Dentistry as part of the 2nd Int. specialize. Exhibition "Dentistry of Belarus" / ed. Minsk: ZAO Technics and Communications, pp. 176-178.

4. Leus P.A. (2011). Diagnostic value of saliva homeostasis in the clinic of therapeutic dentistry: textbook. method. Manual. Belarusian. state honey. un-t; 2nd department therapist. dentistry. Minsk: BSMU, $67 \mathrm{p}$.

5. Terekhova T.N., Leonovich O.M. (2016). Dental status of children with different levels of anxiety to dental interventions. Modern dentistry. No. 1 (62).

6. AAPD. (2014). Guideline on Behavior Guidance for the Pediatric Dental Patient. Pediatric Dentistry. Reference Manual. 36 (6). pp.179-91.

7. Al- Harasi S, Ashley PF, Moles DR, Parekh S, Walters V. (2010). Hypnosis for children undergoing dental treatment. Cochrane Database Syst Rev.; 04 (8): CDo07154. DOI: 10.1002 / 14651858.CDo07154.pub2.

8. Arrow P, Klobas E. (2015). Minimum intervention dentistry approach to managing early childhood caries: a randomized control trial. Community Dent Oral Epidemiol.; 43 (6): 511-520. DOI: 10.1111 / cdoe.12176.

9. Beaton L, Freeman R, Humphris G. (2014). Why are people afraid of the dentist? Observations and 
explanations. Med Princ Pract.; 23. pp.295-301.

10. Bergmann J, Leitão J, Kultje C, Bergmann D, Clode M. (2005). Removing dentine caries in deciduous teeth with Carisolv: a randomized, controlled, prospective study with sixmonth follow-up, comparing chemomechanical treatment with drilling. Oral health \& preventive dentistry. 3 (2). Available from: http://onlinelibrary.wiley.com/o/cochra ne/clcentral/articles/275/CN-00524275/ frame.html.

11. Bernson JM, Elfstrom ML, Hakeberg $M$. (2013). Dental coping strategies, general anxiety, and depression among adult patients with dental anxiety but with different dental-attendance patterns. Eur J Oral Sci. 121. pp. 270-6.

12. Bray A CA, Donkersgoed $R$, and Hoover S, S L. (2009). An Evidence-Based Report Investigating the Most Effective Method to Reduce Dental Anxiety. Toronto: University of Toronto.

13. Gullone E. (2000). The development of normal fear: a century of research. Clin Psychol Rev. 20. pp.429-51.

14. Hasheminia D, Kalantar Motamedi MR, Ahmadabadi FK, Hashemzehi $H$, Haghighat A. Can Ambient Orange Fragrance Reduce Patient Anxiety During Surgical Removal of Impacted Mandibular Third Molars? Journal of Oral \& Maxillofacial Surgery 2014; 72 (9): 1671-6. DOI: $10.1016 \quad /$ j.joms.2014.03.031.

15. Inglehart $M$, Peters $M$, Flamenbaum $M$, Eboda N, Feigal R. Chemomechanical caries removal in children: an operator's and pediatric patients' responses. Journal of the American Dental Association. 2007138 (1). Available from: http://onlinelibrary.wiley.com/o/cochra ne/clcentral/articles/501/CN0577501/frame.html.

16. Klassen JA, Liang $\mathrm{Y}$, Tjosvold L, Klassen TP, Hartling L. Music for pain and anxiety in children undergoing medical procedures: a systematic review of randomized controlled trials. Ambul Pediatr. 2008 Mar-Apr ; 8 (2): 117-28. DOI: 10.1016 / j.ambp.2007.12.005.

17. Djuraeva, D. D., \& Berdiyeva, Z. M. (2016). Cultural heritage as a factor of human development (on the example of Uzbekistan). Ученый XXI века, 23.

18. Lahmann C, Schoen R, Henningsen P, Ronel J, Muehlbacher M, Loew T, et al. (2008). Brief relaxation versus music distraction in the treatment of dental anxiety: a randomized controlled clinical trial. Journal of the American Dental Association (JADA). 139 (3). pp. 317-24.

19. Maru VP, Kumar A, Badiyani BK, Sharma AR, Sharma J, Dobariya CV. (2014). Behavioral changes in preschoolers treated with / without rotary instruments. Journal of International Society of Preventive \& Community Dentistry. 05 // 4 (2): 77-81. DOI: $10.4103 / 2231-0762.139427$.

20. Moola S, Pearson A, Hagger C. (2011). Effectiveness of music interventions on dental anxiety in pediatric and adult patients: a systematic review. JBI Libr Syst Rev. 9 (18). pp.588-630.

21. Ramos-Jorge J, Marques LS, Homem $M A$, et al. (2013). Degree of dental anxiety in children with and without toothache: a prospective assessment. 
Int J Paediatr Dent Br Paedod Soc Int Assoc Dent Child. 23. pp.125-30.

22. Roshan N, Sakeenabi B. Anxiety in children during occlusal ART restorations in primary molars placed in the school environment and hospital dental setup. Journal of clinical pediatric dentistry $2012 \quad 36 \quad$ (4). Available from: http://onlinelibrary.wiley.com/o/cochra ne/clcentral/articles/809/CN0835809/frame.html.

23. Simon AK, Bhumika TV, Nair NS. (2015). Does atraumatic restorative treatment reduce dental anxiety in children? A systematic review and meta-analysis. Eur J Dent. Apr-Jun; 9 (2): 304-9. DOI: 10.4103 / 1305-7456.156841.

24. Stenebrand A, Wide Boman $U$, Hakeberg M. (2013). Dental anxiety and symptoms of general anxiety and depression in 15-year-olds. Int J Dent Hyg.; 11: 99-104.

25. Stenebrand, A., Wide Boman, U., \& Hakeberg, M. (2013). General fearfulness, attitudes to dental care, and dental anxiety in adolescents. European Journal of Oral Sciences, 121(3pt2), 252-257.

26. Umamaheshwari, N., Asokan, S., \& Kumaran, T. S. (2013). Child friendly colors in a pediatric dental practice. Journal of Indian Society of Pedodontics and Preventive Dentistry, 31(4), 225.

27. Wide Boman $U$, Carlsson V, Westin $M$, Hakeberg M. (2013). Psychological treatment of dental anxiety among adults: a systematic review. Europea $\mathrm{n}$ journal of oral sciences. Jun; 121 (3 Pt 2): 225-34. DOI: 10.1111/eos.12032. 